\title{
Características de fetos avaliados por suspeita de anencefalia em um serviço de medicina fetal de referência do Sul do Brasil
}

\author{
Sartori, G.D.P.; Gonzáles, J.F.O.; Krieger, E.R.; Foscarini, A.C.; Rosa, R.F.M.; \\ Apresentador: Ana Carolina Foscarini
}

\section{Resumo}

Introdução: a anencefalia é considerada uma malformação frequente do sistema nervoso central, cujo diagnóstico na gestação vem sendo possível há mais de 40 anos. Nosso objetivo foi descrever a evolução de fetos avaliados por suspeita de anencefalia em um Serviço de Medicina Fetal do Sul do país. Método: a amostra foi composta por pacientes encaminhadas por suspeita de anencefalia fetal ao Serviço de Medicina Fetal do Hospital Materno Infantil Presidente Vargas, no período de 2007 a 2013. Foi realizada uma análise retrospectiva, com coleta de dados clínicos, radiológicos, patológicos e prognósticos. Resultados: a amostra foi composta por 24 gestantes. Suas idades na primeira avaliação variaram de 14 a 42 anos (mediana de 25 anos). Todos os casos da amostra foram de gestações únicas. A suspeita de anencefalia foi realizada em média com 21 semanas de gestação (variou de 12 a 34 semanas). Em 10 casos, houve pedido de interrupção legal da gravidez. O momento da interrupção variou de 18 a 30 semanas de gestação (média de 23,6 semanas). Três pacientes apresentaram morte fetal intrauterina antes da mesma. Das gravidezes que não foram interrompidas ( $\mathrm{n}=14), 4$ (29\%) evoluíram com morte intrauterina. Em relação aos fetos que nasceram vivos, a maioria (80\%) o fez de parto normal.
Em 17 casos (71\%) o diagnóstico de anencefalia foi confirmado. Ao comparar o grupo de pacientes com anencefalia com o restante da amostra, não houve diferença de prognóstico entre ambos (todos foram a óbito até o quarto dia de vida). Conclusões: a anencefalia é uma condição grave, onde os fetos usualmente apresentam morte intrauterina ou evoluem para o óbito precoce após o nascimento. Chama a atenção em nossa amostra que mesmo as condições que fizeram parte do diagnóstico diferencial com anencefalia apresentaram uma evolução bastante grave.

\section{Referência:}

Sartori, G.D.P.; Gonzáles, J.F.O.; Krieger, E.R.; Foscarini, A.C.; Rosa, R.F.M.;. Características de fetos avaliados por suspeita de anencefalia em um serviço de medicina fetal de referência do Sul do Brasil. In: II Congresso Brasileiro de Medicina Hospitalar - II CBMH [= Blucher Medical Proceedings, vol.1, num.5] São Paulo: Editora Blucher, 2014. p.58 DOI 10.5151/medpro-II-cbmh-053 